\title{
Wireless Phone Threat Assessment for Aircraft Communication and Navigation Radios
}

\author{
T. X. Nguyen, S. V. Koppen, L. J. Smith, R.A. \\ Williams \\ NASA Langley Research Center, Hampton, VA \\ Email: Truong.x.Nguyen@nasa.gov
}

\author{
M. T. Salud \\ Lockheed Martin, Hampton, VA
}

\begin{abstract}
Emissions in aircraft communication and navigation bands are measured for the latest generation of wireless phones. The two wireless technologies considered, GSM/GPRS and CDMA2000, are the latest available to general consumers in the U.S. A base-station simulator is used to control the phones. The measurements are conducted using reverberation chambers, and the results are compared against FCC and aircraft installed equipment emission limits. The results are also compared against baseline emissions from laptop computers and personal digital assistant devices that are currently allowed to operate on aircraft.
\end{abstract}

Keywords- Aircraft; interference; wireless phone; CDMA2000, GSM; GPRS; reverberation chamber

\section{INTRODUCTION}

Wireless markets and technologies have experienced phenomenal growth in the recent years. Two technologies that saw the most growth are wireless phones and wireless local area networks (WLANs). These technologies enabled a revolution in accessibility and productivity as they enabled consumers to have convenient access to the internet, email, instant messaging and numerous other applications.

For various reasons, use of wireless phones is currently prohibited while the aircraft is in the air. However, with a high percentage of travelers owning wireless phones, occasional unintended use, as well as unauthorized intended use is expected.

Recent flight demonstrations show that wireless phone use on airplanes is technically possible. In these demonstrations, wireless phones communicated with the on-board picocell base-stations rather than directly with the ground towers, thereby reducing the possibility of interfering with the ground cellular networks. Plane to ground communications were provided through satellite links.

Unlike aircraft installed equipment, passenger carry-on devices such as wireless phones are not required to pass the rigorous aircraft radiated field emission limits. It is therefore the goal of this study to measure the emissions from wireless phones in aviation bands and to assess interference risks to aircraft systems.

Built upon the process and results from the previous efforts [1][2], this study revisits the phone emissions topic. The current effort focuses on the latest generation of phones that are more data-capable. In specific, the two latest and popular technologies used in the US are the CDMA2000 1xRTT (1x
Radio Transmission Technology) and the GSM/GPRS (General Packet Radio Service). Phones operating in $850 \mathrm{MHz}$ and $1900 \mathrm{MHz}$ range are addressed. Testing in both voice and data modes are conducted.

For simplicity, the terms CDMA and GSM in this paper refer to the wireless technologies unless otherwise noted. The CDMA is expanded to CDMA2000 1xRTT technology or devices. Likewise, the GSM term is expanded to GSM/GPRS technology and devices. The distinction is only made when GSM refers to voice communication mode, while GPRS refers to data mode.

\section{SCOPE}

Assessment of aircraft radio receiver interference is typically accomplished by addressing the three elements of the equation:

$$
\mathrm{A}+\mathrm{B} \geq \mathrm{C},
$$

where " $\mathrm{A}$ " is the maximum RF emission from the offending device in $\mathrm{dBm}$; " $\mathrm{B}$ " is the aircraft receiver maximum interference coupling factor in $\mathrm{dB}$; "- $\mathrm{B}$ ", in $\mathrm{dB}$, is commonly referred to as the minimum interference path loss (IPL); "C" is the receiver's minimum in-band on-channel interference threshold in $\mathrm{dBm}$.

If the minimum interference threshold, "C", is lower than the maximum interference signal level at the receiver's antenna port, " $(\mathrm{A}+\mathrm{B})$ ", there is a potential for interference.

The emphasis of this paper is to document the measurements and results of the maximum RF emission, " $\mathrm{A}$ ", from wireless phones. "B" and "C" are determined from earlier efforts [1][2] and are not addressed here due to the page limitation. However, the remaining analysis can be found in [3].

In addition, the results are restricted to unintentional emissions in and near aircraft radio spectrum. Intentional emissions, or desired emissions for the purpose of voice and data communication, are typically known or easily determined and are not considered in this study.

\section{APPROACH}

Various aircraft radio bands of interest were grouped into five measurement bands to reduce the number of 
measurements and test time. Aircraft radio bands that overlapped, or were near one another were grouped together, and emissions were measured across the entire combined band simultaneously. Five measurement band groups, designated as Band 1 to Band 5, covered aircraft radio bands such as Localizer (LOC), Very High Frequency Voice Communication (VHF-Com), VHF Omni-directional Range (VOR), Glideslope (GS), Traffic Collision Avoidance System (TCAS), Air Traffic Control Radar Beacon System (ATCRBS), Distance Measuring Equipment (DME), Global Positioning System (GPS), and Microwave Landing System (MLS). Table I correlates the measurement bands and the listed aircraft radio bands.

It is implied that high emissions anywhere in a measurement band potentially affect all systems grouped in that band. No effort is made to distinguish whether the emissions were on any specific radio band or channel.

Two reverberation chambers were used to conduct the measurements, producing results in the form of total radiated power (TRP) [4]. This method differs from the approach used in RTCA/DO-199 [5], where the equivalent power was estimated from the electric field measured at a given distance

TABLE I. EMISSION MEASUREMENT BAND DESIGNATIONS

\begin{tabular}{|c|c|c|c|}
\hline $\begin{array}{l}\text { Meas. } \\
\text { Bands }\end{array}$ & $\begin{array}{c}\text { Meas. Freq. } \\
\text { Range (MHz) }\end{array}$ & $\begin{array}{c}\text { Aircraft Systems } \\
\text { Covered }\end{array}$ & $\begin{array}{c}\text { Spectrum } \\
(\mathrm{MHz})\end{array}$ \\
\hline \multirow{3}{*}{ Band 1} & \multirow{3}{*}{$105-140$} & LOC & $108.1-111.95$ \\
\hline & & VOR & $108-117.95$ \\
\hline & & VHF-Com & $118-138$ \\
\hline Band 2 & $325-340$ & GS & $328.6-335.4$ \\
\hline \multirow{5}{*}{ Band 3} & \multirow{5}{*}{$960-1250$} & TCAS & 1090 \\
\hline & & ATCRBS & 1030 \\
\hline & & DME & $962-1213$ \\
\hline & & GPS L2 & 1227.60 \\
\hline & & GPS L5 & 1176.45 \\
\hline Band 4 & $1565-1585$ & GPS L1 & $1575.42 \pm 2$ \\
\hline Band 5 & $5020-5100$ & MLS & $5031-5090.7$ \\
\hline
\end{tabular}

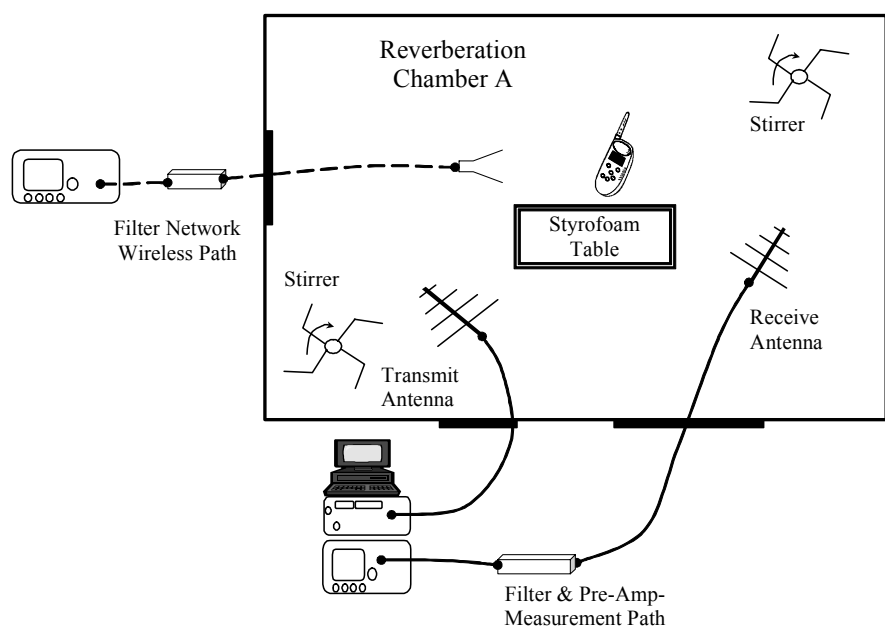

Figure 1. Reverberation chamber and wireless phone emission test configuration

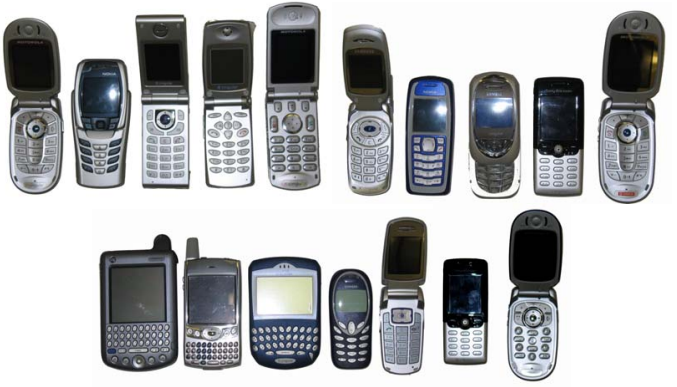

Figure 2. The GSM Test Phones (not to scale)

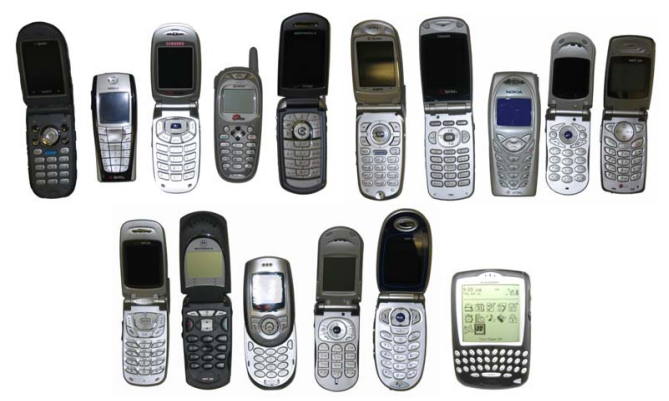

Figure 3. The CDMATest Phones (not to scale)

from a device-under-test. Additional details on the reverberation method testing are in the next section.

Each wireless phone was tested individually, and was controlled using a wireless base-station simulator (BSS). Located outside the test chamber, the BSS communicated with a test phone in the test chamber via a filter network and a wideband antenna. The BSS commanded the test phone to operate in various voice/data modes, frequency channels and data rates while emission data were being collected. The filter network passed the desired wireless signal while preventing any spurious emissions from the BSS from contaminating the environment in the test chamber. Fig. 1 shows the test chamber and the equipment set-up.

The devices considered included 17 phones using GSM technology and 16 phones using CDMA technology (Fig. 2 and 3). Most of these devices were new, and active service subscriptions were not required for communicating with a BSS. The specific brands and models can be found in [3].

The measured results were compared against the emissions from common computer laptops and PDAs previously reported in [2]. The PDAs/laptop computers emission data establish a baseline for devices that are currently allowed on an aircraft. The results were also compared against corresponding FCC wireless phone spurious emission limits, FCC Part 15 limits for non-intentional transmitters, and the RTCA aircraft installed equipment limits.

\section{Wireless PhONE TEST MOdes}

It is not the intention of this paper to compare the CDMA phones against the GSM phones. However, due to the different design features and the test modes selected, the testing and the results were grouped into two distinct groups. All the GSM 
phones were tested using a similar set of test modes, whereas the CDMA phones were tested using a different set of test modes. However, the test mode selections shared these common guidelines:

- $\quad$ Voice mode

- Data modes, at four different data rates

- Cellular and PCS bands (if supported by the phone)

- $\quad$ Five frequency channels, equally spaced, spanning across each of the cellular and PCS bands

- Maximum phone transmission power

- Idle mode and "No BSS Signal" idle mode

The actual test modes selected were dictated by the common set of capabilities of the phones and of the BSS, and typical usage. The number of test modes was also constrained by the total test time. The combinations totaled to approximately 1785 and 1680 separate measurements for the 17 GSM phones and 16 CDMA phones, respectively. Tables II and III summarize the test modes selected.

\section{MEASUREMENT METHOD}

\section{A. Reverberation Chamber Test Method}

Reverberation chambers were used because of their excellent repeatability, field uniformity, aspect independence, and speed. The results are in the form of total radiated power rather than in field strength. A disadvantage of testing wireless devices in reverberation chamber include occasional difficulties in establishing and maintaining connectivity with the wireless devices due to severe multipath interference.

Two reverberation chambers were used for the five measurement bands. The larger chamber, designated as Chamber A, had the lowest usable frequency of approximately $80 \mathrm{MHz}$ and was used for Band 1 and Band 2. The smaller chamber, designated as Chamber $\mathrm{C}$, had the lowest usable frequency of about $350 \mathrm{MHz}$ and was used for Band 3, Band 4 and Band 5. The smaller chamber has lower chamber loss, resulting in better measurement sensitivity at higher bands.

Due to the chamber quality factor and the associated chamber time constant $(0.6 \mu \mathrm{sec}$ near $100 \mathrm{MHz})$, it was assumed that most measured signals were continuous-wave (CW) or pulse modulated with $1.5 \mu$ sec pulse-width or longer [4].

The mode-stirred method was adopted due to ease of implementation and speed. In the mode-stirred method, the stirrer continuously rotated rather than stepped as in the modetuned method. The stirrers located in the corners of the chamber rotated at $5 \mathrm{rpm}$ during both chamber calibrations and testing.

Fig. 4 and Fig. 5 show the emission test setup in a reverberation chamber, and the data acquisition system outside the test chamber. The wireless BSS was located outside the chamber to avoid contaminating the test environment.
TABLE II. CDMA2000 PHONE TEST MODES

\begin{tabular}{|c|c|c|c|}
\hline Test Modes & $\begin{array}{c}\text { No. of } \\
\text { Cell } \\
\text { Band } \\
\text { Channels }\end{array}$ & $\begin{array}{c}\text { No. of } \\
\text { PCS } \\
\text { Band } \\
\text { Channels }\end{array}$ & $\begin{array}{l}\text { Test Time } \\
\text { (minutes) }\end{array}$ \\
\hline Voice & 5 & 5 & 2 per channel \\
\hline $\begin{array}{l}\text { Data } \\
\text { (Fundamental Chanel) }\end{array}$ & 5 & 5 & 2 per channel \\
\hline $\begin{array}{l}\text { Data } \\
\text { (SupplementalChannel) } \\
9.6 \mathrm{kbps} \\
38.4 \mathrm{kbps} \\
153.6 \mathrm{kbps}\end{array}$ & $\begin{array}{l}5 \\
5 \\
5\end{array}$ & $\begin{array}{l}5 \\
5 \\
5\end{array}$ & $\begin{array}{l}5 \text { per } 5 \text { channels } \\
5 \text { per } 5 \text { channels } \\
5 \text { per } 5 \text { channels }\end{array}$ \\
\hline Idle & 1 & 1 & 2 per channel \\
\hline Idle (No BSS Signal) & None & None & 2 \\
\hline
\end{tabular}

TABLE III. GSM/GPRS PhONE TEST MODES

\begin{tabular}{|c|c|c|c|c|}
\hline $\begin{array}{c}\text { Test } \\
\text { Modes }\end{array}$ & $\begin{array}{c}\text { GPRS } \\
\text { MS Config } \\
\text { [Down, Up] }\end{array}$ & $\begin{array}{c}\text { No. of } \\
\text { Cell Band } \\
\text { Channels }\end{array}$ & $\begin{array}{c}\text { No. of } \\
\text { PCS } \\
\text { Band } \\
\text { Channels }\end{array}$ & $\begin{array}{c}\text { Test Time } \\
\text { (minutes) }\end{array}$ \\
\hline Voice & & 5 & 5 & 2 per channel \\
\hline Data & {$[1,1]$} & 5 & 5 & 5 per 5 channels \\
(GPRS & {$[2,1]$} & 5 & 5 & 5 per 5 channels \\
Mode) & {$[4,1]$} & 5 & 5 & 5 per 5 channels \\
& {$[2,2]$} & 5 & 5 & 5 per 5 channels \\
Idle & & 1 & 5 & 5 per 5 channels \\
\hline Idle & & None & None & 2 \\
(No & & & & \\
BSS ) & & &
\end{tabular}

A chamber calibration was first performed. In this step, a known level of power was delivered from the source into the chamber through the transmit antenna. The spectrum analyzer was used to record the maximum power coupled into the receive antenna (and the receive path) while performing synchronized frequency sweeps with the tracking source. The difference, in $\mathrm{dB}$, between the injected power and the measured power determined the chamber calibration factor (after correcting for appropriate cable and other system losses).

During the emission measurements, the DUT was set to

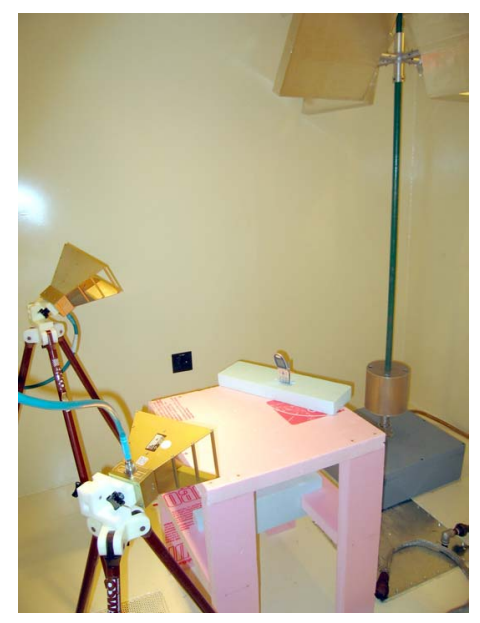

Figure 4. A sample set up in a small test chamber. The front antenna is for communicating with the phone under test. 


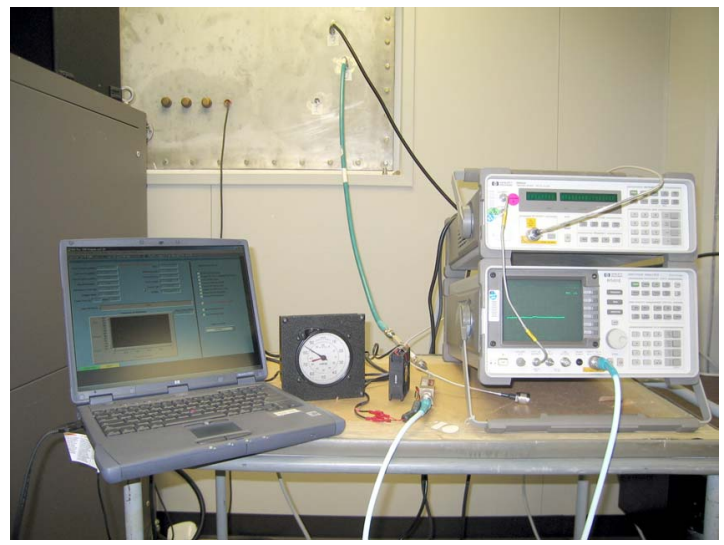

Figure 5. Control and Data Acquisition Set-Up outside the Test Chamber

operate in desired operating modes. The spectrum analyzer's trace was set on maximum hold mode while continuously sweeping over the measurement frequency band. Finally, chamber calibration factors were applied to arrive at the final total radiated power.

\section{B. Filters and Amplifiers}

Proper filtering was required for accurate measurement of spurious emissions from the wireless phones. Two separate sets of custom filters were used, one in the wireless path and the other in the measurement path. In the wireless path, the filters were to block any undesired signal from the wireless BSS from contaminating the test chamber while passing the wireless signals. In the measurement path, another set of filters were to block the high power wireless signals from overloading the measurement instruments or the pre-amplifiers while passing the desired measurement band(s). The pre-amplifiers were used in the measurement path to improve system sensitivity.

The filter network in the wireless path was positioned between the BSS and its antenna. The filter network consisted of two separate cellular and PCS band filters in parallel to pass both bands simultaneously. This set-up allows the BSS to switch seamlessly between the wireless bands without changing filters as it is necessary to test dual band phones. This set-up can also be expanded to include other frequency bands.

The filters and amplifiers were present during both the calibration and measurement. Their effects on the measurement data were automatically accounted for in the process.

\section{MEASUREMENT RESUlts}

The phone test modes include combinations of voice mode, various data rates, frequency channels, and operating bands (cellular or PCS). In this paper, only the maximum emission envelopes in Band 3 are shown for a limited number of phones. The remaining data can be found in [3].

The results are grouped into CDMA and GSM groups. Sample results are shown in Fig. 6 and 7 for five phones in

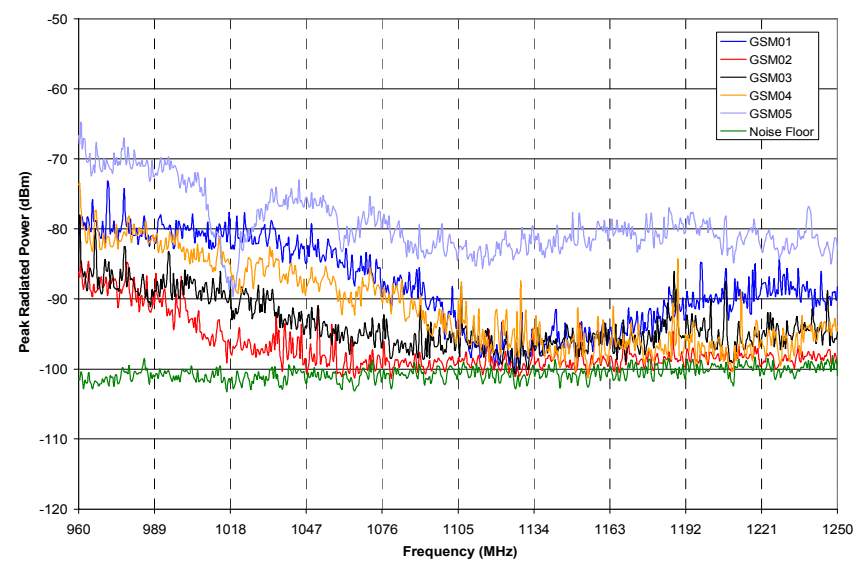

Figure 6: Sample GSM Phones Maximum Emissions in Band 3

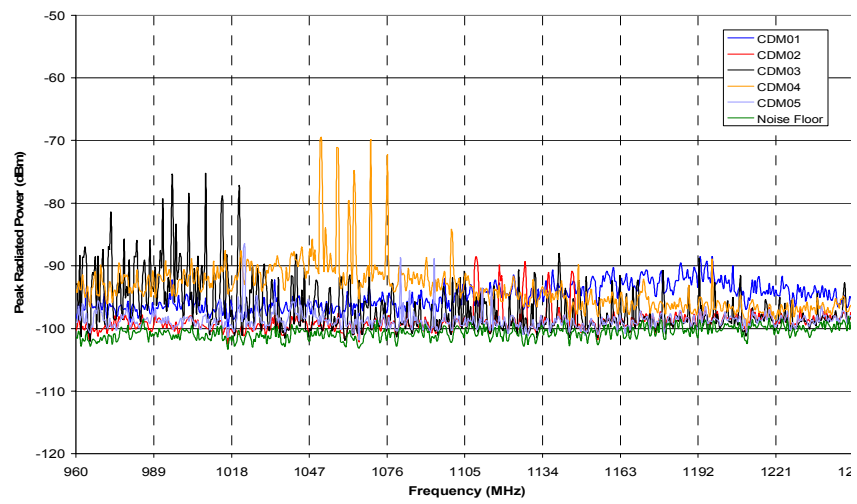

Figure 7. Sample CDMA Phones Maximum Emissions in Band 3

each group. In addition, a noise floor is shown to represent the spectrum analyzer noise floor that was processed in the same way as the data. This noise floor establishes the sensitivity of the measurement system.

Fig. 8 and 9 present the summary plots of the peak emission values for all the phones operating in combinations of voice/data modes and cellular/PCS bands. These summary charts can be used to quickly compare results and to identify phones that behave abnormally from their peers in term of the maximum emission levels.

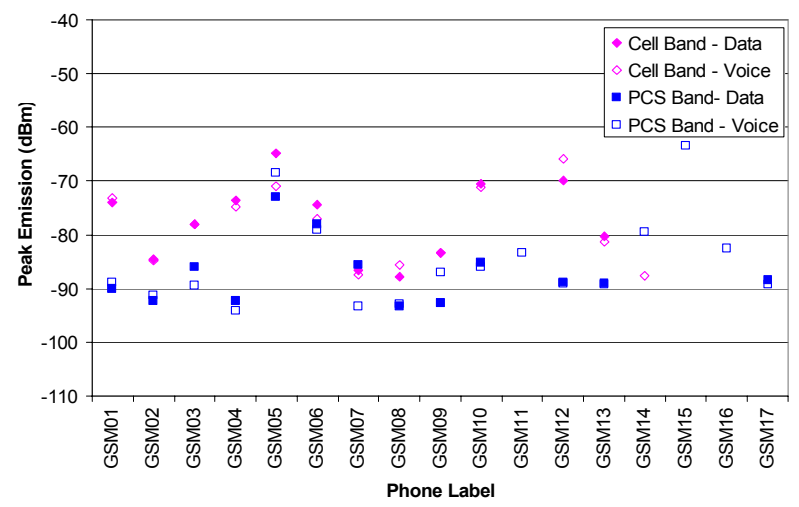

Figure 8. GM/GPRS Phones Maximum Emissions in Band 3 


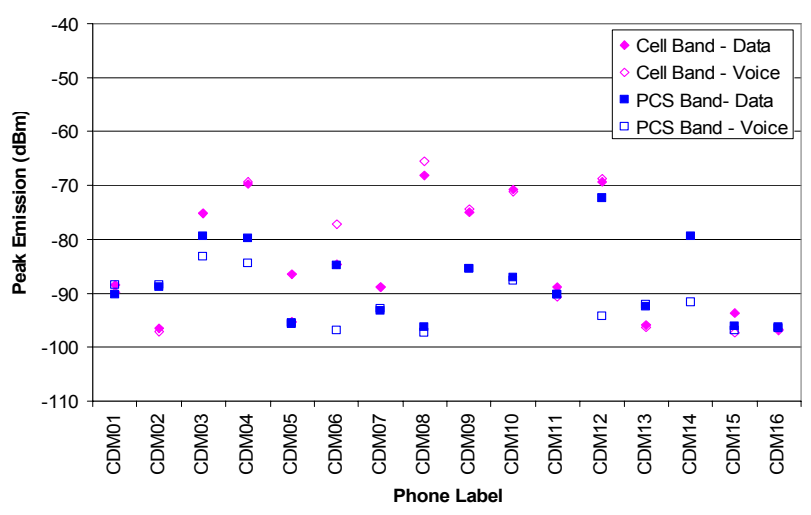

Figure 9. CDMA2000 Phones Maximum Emissions in Band 3

\section{Results COMPARISON WITH Allowed DeVICES EMISSIONS AND REGULATORY LIMITS}

\section{A. Baseline Emissions from Laptop Computers and PDAs}

Spurious radiated emissions were recorded for eight laptop computers, with each operating in five modes: idle, screensaver, file transferring, CD playing, and DVD playing. Two Personal Digital Assistants (PDA) operating in idle and file transfer modes were also considered. The maximum emission envelopes for the devices are compared against wireless phones' emissions. Again, only the results for Band 3 are shown (Fig. 10) due to page limitation. However, detailed measurement results can be found in [2].

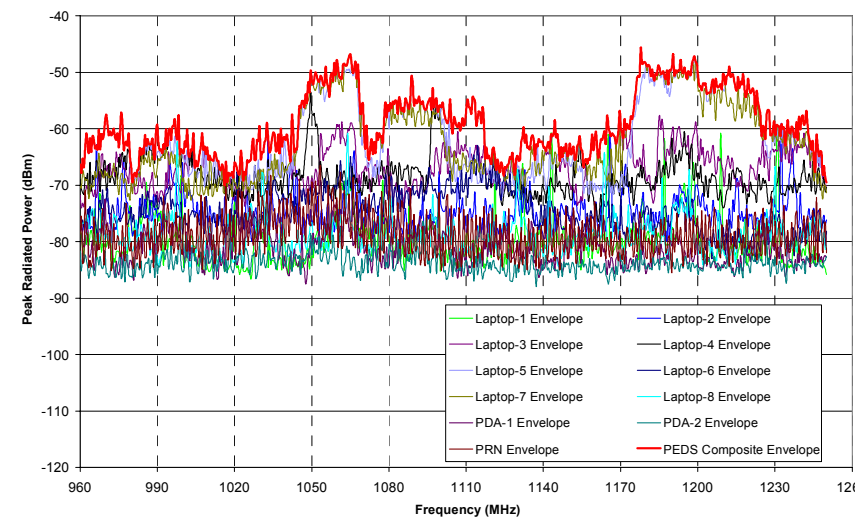

Figure 10. Laptops/PDA Emissions in Band 3

\section{B. FCC and Aircraft Installed Equipment Emission Limit}

RTCA/DO-160 [4] Section 21 Category M emission limit is selected for comparisons with emissions from passenger carryon devices. This limit is designated for installed equipment in the passenger cabin or in the cockpit of a transport aircraft, where apertures (such as windows) are electromagnetically significant. Similarly, FCC Part 15.109 [6] limits for unintentional radiators (such as laptop computers), and the spurious emission limits for wireless phones in the cellular [7] and PCS bands [8] are also used in the comparison.

The emission limits are converted from field strength to effective-isotropic-radiated-power (EIRP) using:

$$
E I R P=\frac{E^{2} \cdot 4 \pi R^{2}}{120 \pi}(\text { Watts })
$$

where $E=$ Electric Field Intensity at distance R $(\mathrm{V} / \mathrm{m})$

$$
R \quad=\text { Distance }(\mathrm{m}) \text {. }
$$

EIRP can be converted to $\mathrm{dBm}$ using the $10 *$ $\log \left(1000^{*} E I R P\right)$. Ref. [2] provides additional details on the limits and the equivalent power levels.

Table IV and Fig. 11 summarize the maximum emission levels from all the phones and compare them against the maximum laptop emissions and the emission limits. The limit value for each measurement band is conservatively chosen to be the lowest limit value of the aircraft bands within it. The results are shown in "total radiated power" $(T R P)$ where as the emission limits are usually given in EIRP or effective-radiatedpower $(E R P)$. The next subsection provides an estimate of the uncertainty in the comparison due to unknown device directivity.

TABLE IV. MAXIMUM EMISSION FROM WIRELESS PHONES IN AIRCRAFT BANDS (IN DBM)

\begin{tabular}{|c|ccc|c|}
\hline $\begin{array}{c}\text { Meas. } \\
\text { Band }\end{array}$ & $\begin{array}{c}\text { Cell Band } \\
\text { Phones } \\
\text { (GSM \& } \\
\text { CDMA) }\end{array}$ & $\begin{array}{c}\text { PCS Band } \\
\text { Phones } \\
\text { (GSM \& } \\
\text { CDMA) }\end{array}$ & $\begin{array}{c}\text { Baseline } \\
\text { Laptops } \\
\text { PDAs }\end{array}$ & $\begin{array}{c}\text { Aircraft } \\
\text { Bands }\end{array}$ \\
\hline Band 1 & -75.3 & -76.8 & -63.3 & $\begin{array}{c}\text { LOC, VOR, } \\
\text { VHF-Com }\end{array}$ \\
\hline Band 2 & -79.5 & -75.8 & -58.7 & GS \\
\hline Band 3 & -64.7 & -63.3 & -45.7 & $\begin{array}{c}\text { TCAS, DME, } \\
\text { GPS L2 }\end{array}$ \\
\hline Band 4 & -85.8 & -66.5 & -55.8 & GPS L1 \\
\hline Band 5 & -43.8 & -63.8 & -77.0 & MLS \\
\hline
\end{tabular}

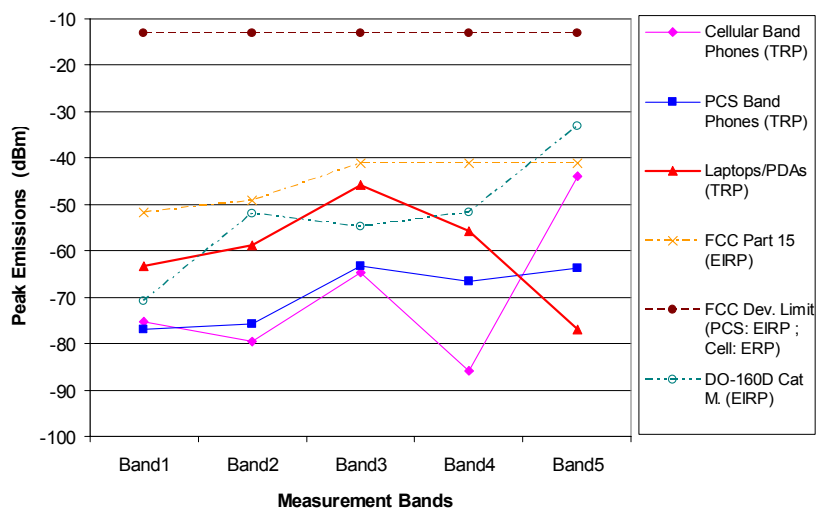

Figure 11. Emissions from Wireless Phones and Comparison with Emission Limits

\section{Device Directivity}

Emissions measured using a reverberation chamber provide results in TRP within the measurement resolution bandwidth. TRP is different from EIRP and ERP except for antennas or devices with an isotropic radiation pattern. Rather, 


$$
\begin{aligned}
& \operatorname{EIRP}(\mathrm{dBm})=\operatorname{TRP}(\mathrm{dBm})+D_{G}(\mathrm{~dB}), \text { and } \\
& \operatorname{ERP}(\mathrm{dBm})=\operatorname{EIRP}(\mathrm{dBm})-2.15(\mathrm{~dB}),
\end{aligned}
$$

where $D_{G}$ is the directivity, or maximum directive gain of the test device. Comparing TRP directly with EIRP can lead to an uncertainty equal to the $D_{G}$. $D_{G}$ is usually difficult to measure since maximum radiation angles and mechanisms for spurious emissions are often not known. However, [9] provided a statistical approach to estimate the expected $D_{G}$ for unintentional emissions. Using the equations provided in [9], Fig. 12 shows the expected $D_{G}$ for the largest test wireless phone (20 $\mathrm{cm}$ maximum dimension), which varies between 5 and $8 \mathrm{~dB}$ for the five measurement bands.

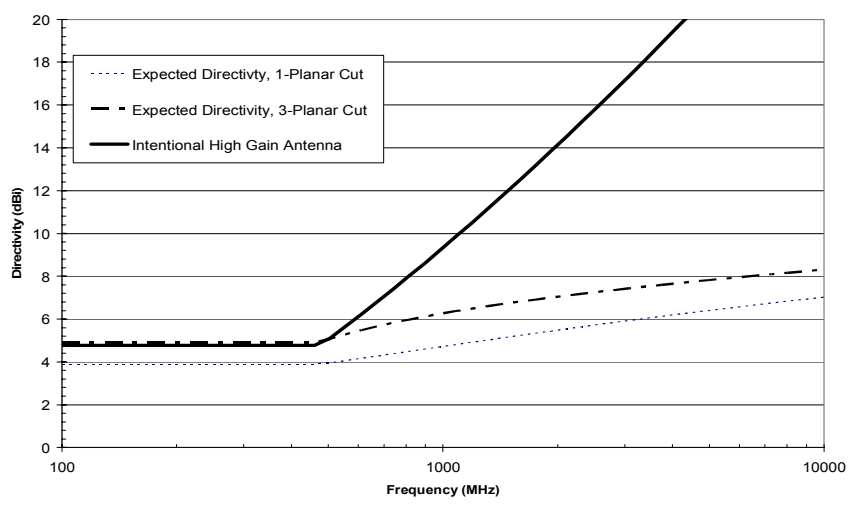

Figure 12. Expected Directivity for a $20 \mathrm{~cm}$ (8 inches) Unintentional Transmitter

\section{SUMMARY AND CONCLUSIONS}

The following summary and conclusions were made based on the presented data as well as the more detailed results reported in [3]:

- The 33 wireless phones tested did not generate higher emissions than standard laptop computers in most aircraft bands considered (Bands 1-4). The exception is the MLS band (Band 5), where the emissions from the phone exceeded the emissions from the laptop computers.
- The spurious emissions from the phones were also below the aircraft installed equipment limits (RTCA/DO-160 Cat. $\mathrm{M})$, even with the consideration of the 5 to $8 \mathrm{~dB}$ uncertainty associated with the phones expected directivity

- Voice and data mode spurious emissions were generally similar (within 2-5 dB) in most cases. In addition, emission results for cellular band versus PCS band operations were similar for measurement in Band 1 and Band 2. It was not the case for the remaining Band 3 to Band 5.

\section{ACKNOWLEDGEMENTS}

This work was funded by the FAA Aircraft Certification Office and the NASA Aviation Safety Program.

\section{REFERENCES}

[1] Ely, J. J.; Nguyen T. X.; Koppen, S. V.; Salud, M. T.; and Beggs J. H.: "Wireless Phone Threat Assessment and New Wireless Technology Concerns for Aircraft Navigation Radios", NASA/TP-2003-212446, July 2003.

[2] T. Nguyen, S. Koppen, J. Ely, R. Williams, L. Smith and M. Salud, "Portable Wireless LAN Device and Two-Way Radio Threat Assessment for Aircraft Navigation Radios", NASA/TP-2003-212438, July 2003; and "...for Aircraft VHF Communication Radio Band", NASA/TM-2004-213010, March 2004.

[3] T. Nguyen, S. Koppen, L. Smith, R. Williams, and M. Salud "Third Generation Wireless Phone Threat Assessment for Aircraft Communication and Navigation Radios" NASA/TP-2005-213537, March 2005; http://techreports.larc.nasa.gov/ltrs/PDF/2005/tp/NASA2005-tp213537.pdf.

[4] RTCA/DO-160D, Change No. 1, Environmental Conditions and Test Procedures for Airborne Equipment, December 14, 2000.

[5] RTCA/DO-199, "Potential Interference to Aircraft Electronic Equipment from Devices Carried Aboard", September 16, 1988.

[6] FCC 15.109 "Radiated Emission Limits", December 19, 2001.

[7] FCC 22.917 "Cellular Radiotelephone Service - Emission Limits for Cellular Equipment", 1 October 2003 Edition.

[8] FCC 24.238 "Personal Communication Services - Broadband PCS Emission Limits", 1 October 2003 Edition.

[9] G. Koepke, D. Hill and J. Ladbury "Directivity of the Test Device in EMC Measurements", 2000 IEEE International Symposium on Electromagnetic Compatibility, Aug. 21-25, 2000. 